\title{
Register nominum ad Vol. XXXIV
}

\section{Attinger, E. O., 164}

Balaguer-Vintró, I., v. Nolla-

Panades, J. Batschelet, E., v. Planta, P. von Bayer, O., und Wolter, H. H., 196 (B) Benda, L., Doneff, D., und Moser, K.,

298 Bergmann, K., v. Fejfar, Z. Bienroth, W., v. Engelking, R. Bloch, K, 260 (B) Bonanni, L., v. Masini, V. Bonessa, C, und Morpurgo, M.,

261 (B) Brod, J., v. Fejfar, Z.

Castellanos, A., Garcia, O., and

Gonzalez, E., 53 Chatillon, J. Y., v. Ghazi Vakili, R. Christopoulos, D., v. Doliopoulos, T.

Coates, E. O., v. Pauli, H. G. Concina, B., v. Masini, V. Cottier, H., v. Gürtler, R. Cottier, P., v. Strausak, A.

Desbaillets, P., v. Ilurlimann, J.

-, v. Rivier, J. L.

Doliopoulos, T., Christopoulos, D.,

and Skalkeas, G., 1 Domanig, E., v. Effert, S. Doneff, D., und Scheid, H., 199 -, v. Benda, L·.

Duchosal, P. W., et Grosgurin, J. R.

260 (B) -, v. Rivier, J. L·

Effert, S., Domanig, E., und

147

Erkens, IL·, 73 (S) Engelking, R., und Bienroth, W. Erkens, H., v. Effert. S. 